\title{
AGB1 and PMR5 Contribute to PEN2-Mediated Preinvasion Resistance to Magnaporthe oryzae in Arabidopsis thaliana
}

\author{
Kana Maeda, Yasunari Houjyou, Takuma Komatsu, Hiroki Hori, Takahiro Kodaira, and Atsushi Ishikawa \\ Department of Bioscience, Fukui Prefectural University, Fukui 910-1195, Japan
}

Submitted 7 April 2009. Accepted 30 June 2009.

\begin{abstract}
Rice blast, caused by Magnaporthe oryzae, is a devastating disease of rice (Oryza sativa). The mechanisms involved in resistance of rice to blast have been studied extensively and the rice-M. oryzae pathosystem has become a model for plant-microbe interaction studies. However, the mechanisms involved in nonhost resistance (NHR) of other plants to rice blast are still poorly understood. Here, we investigated interactions between Arabidopsis thaliana and $M$. oryzae to identify the genetic basis of NHR. In A. thaliana accessions, preinvasion resistance to $M$. oryzae in Col-0 was stronger than that of Ler. To examine the genetic basis underlying the natural variation in the responses, we used a well-established set of recombinant inbred lines (RIL) derived from a $\mathrm{Col} \times \mathrm{Ler}$ cross and identified three quantitative trait loci that govern the expression of NHR in $A$. thaliana against $M$. oryzae. Among the penetration (pen) mutants, only the pen 2 mutant allowed increased penetration into epidermal cells by $M$. oryzae. Double mutant analysis indicated that AGB1 and PMR5 contribute to PEN2-mediated preinvasion resistance to $M$. oryzae in $A$. thaliana, suggesting a complex genetic network regulating the resistance. Our results demonstrate that $A$. thaliana can be used to study mechanisms of NHR to M. oryzae.
\end{abstract}

Rice is a staple crop of economic importance in many countries. One of the most serious and widespread diseases of rice is blast, caused by the ascomycete fungus Magnaporthe oryzae. The mechanisms involved in resistance of rice to blast have been studied extensively and the rice- $M$. oryzae pathosystem has become a model for the study of plant-microbe interactions because both whole-genome sequences and functional genomic approaches are available (Koga 2001; Dean et al. 2005; Ebbole 2007; Kankanala et al. 2007; Wilson and Talbot 2009). The infection of rice by $M$. oryzae follows a developmental process that has been observed in many foliar fungal pathogens. A germ tube produced from the conidium differentiates into a specialized infectious structure called the appressorium, which adheres tightly to the plant surface using mucilage. The fungus generates massive turgor pressure inside the melanized appressorium and a thin penetration peg pierces the host surface, using this pressure to enter a leaf epidermal cell (Howard et al. 1991). After penetration, the peg differentiates into bulbous and lobed infectious hyphae that grow intracellularly and intercellularly.

Corresponding author: Atsushi Ishikawa; Telephone:+81-776-61-6000; Fax: +81-776-61-6015; E-mail: ishikawa@ @fpu.ac.jp
Most plants are immune to the majority of would-be pathogens and susceptible to only a relatively small number of adapted microbes. Consequently, disease is the exception and not the rule. Disease resistance shown by an entire plant species to all genetic variants of a nonadapted pathogen species is the most common form of plant immunity and termed nonhost resistance (NHR) (Heath 2000; Lipka et al. 2008). Although NHR represents the most common and durable form of plant resistance in nature, it has thus far been poorly understood at the molecular level.

Recently, Arabidopsis thaliana mutants with altered nonhost interactions upon Blumeria graminis hordei infection were identified and three genes-PENETRATION 1 (PEN1), PEN2, and PEN3-were identified (Collins et al. 2003; Lipka et al. 2005; Kobae et al. 2006; Stein et al. 2006). Single mutants of these genes exhibit several-fold increased invasion frequencies by $B$. graminis hordei but no increase in overall susceptibility owing to concomitant hypersensitive response (HR)-like cell death of invaded epidermal cells. PEN1 encodes a plasma membrane-anchored syntaxin with a soluble N-ethylmaleimidesensitive factor attachment protein receptor (SNARE) domain (Collins et al. 2003). SNARE-domain-containing proteins are key players in vesicle-associated membrane fusion and secretion processes, including exocytosis and endocytosis. PEN2 encodes 1 of 48 predicted $A$. thaliana family 1 glycoside hydrolases (F1GHs) (Lipka et al. 2005). Recently, it has been found that PEN2 is an atypical myrosinase (a type of $\beta$-thioglucoside glycohydrolase), which is involved in a glucosinolate metabolism in defense responses (Bednarek et al. 2009; Clay et al. 2009). PEN3 encodes one of the 15 pleiotropic drug resistance (PDR) ATP binding cassette (ABC) transporters present in the A. thaliana genome (Kobae et al. 2006; Stein et al. 2006). These are ubiquitous transmembrane proteins that function in the ATP-dependent transport of a wide variety of substrates across extracellular and intracellular membranes. A. thaliana mutants showing enhanced entry are still nonhost plants for nonadapted powdery mildews owing to effective postentry cell death. Systematic analyses with multiple mutant combinations revealed that posthaustorial NHR requires enhanced susceptibility 1 (EDS1), phytoalexin-deficient 4 (PAD4), and senescence-associated gene 101 (SAG101) (Lipka et al. 2005). Single mutants for EDS1, PAD4, and SAG101 have no or only a minor effect on preinvasion resistance to powdery mildews. However, pen2-pad4-sag101 triple mutants are fully susceptible for the nonadapted pea powdery mildew and allow the monocot pathogen $B$. graminis hordei to establish basic compatibility (Lipka et al. 2005). Thus, A. thaliana NHR to nonadapted biotrophic powdery mildews is based upon two successive, multicomponent, and independently effective de- 
fense layers: PEN-mediated preinvasion resistance and postinvasion immunity, controlled by EDS1, PAD4, and SAG101 (Lipka et al. 2005). In addition, NHR of A. thaliana to other pathogens has also been studied (Huitema 2003; Yun et al. 2003; Shimada et al. 2006; Shafiei 2007; Loehrer et al. 2008).

The involvement of well-described defense-related genes has been investigated in NHR. The salicylic acid (SA) signal transduction pathway plays an important role in defense responses initiated by resistance $(R)$ genes. However, its contribution to NHR is less clear. A. thaliana plants expressing $N a h G$, which converts SA to catechol (Lawton et al. 1995), do not accumulate SA and are compromised in NHR to some but not all bacterial and fungal pathogens (Lu et al. 2001; Mellersh and Heath 2003; Van Wees and Glazebrook 2003; Yun et al. 2003). The jasmonate and ethylene (JA/ET) pathway has also been tested for its role in NHR. In A. thaliana, blocks in the JA or ET pathways generally did not promote enhanced susceptibility to nonhost pathogens (Mellersh and Heath 2003; Yun et al. 2003). Heterotrimeric $G$ protein complexes couple extracellular signals to downstream effectors via cell surface receptors. Although recent studies have shown that the A. thaliana heterotrimeric G proteins are involved in defense responses against several pathogens (Suharsono et al. 2002; Trusov et al. 2006, 2008; Ishikawa 2009), their contribution to NHR is less clear. Specific host genes or proteins termed compatibility or susceptibility factors are believed to be essential for successful pathogenesis by a given microbe, and a lack of these factors is predicted to result in resistance to an otherwise virulent pathogen (Jones and Dangl 2006). In a screen to recover loss-of-susceptibility to Golovinomyces cichoracearum mutants in A. thaliana, the powdery mildew resistant (pmr) mutants pmrl to pmr6 were isolated and some of the genes have been cloned (Vogel and Somerville 2000). PMR2 is allelic to MLO2 (Consonni et al. 2006), PMR4 encodes a wound- and pathogen-associated callose synthase (Jacobs et al. 2003; Nishimura et al. 2003), PMR5 belongs to a large family of plant-specific genes of unknown function (Vogel et al. 2004), and PMR6 encodes a glycosyl-phosphatidyl-inositol (GPI)-anchored pectate-lyase-like protein (Vogel et al. 2002). However, their contribution to NHR is poorly understood.

Recently, Faivre-Rampant and associates (2008) have initiated the characterization of NHR in rice challenged with $M$. grisea strains isolated from other monocot species and compared it with compatible or incompatible interactions of rice with strains of the $M$. oryzae species isolated from wheat and rice. However, the mechanisms involved in NHR of nonhost plants to rice blast are still poorly understood, although the cytological description of events occurring during a rice blast infection on these plants was investigated as early as the 1940s (Yoshii 1949; Hashioka and Kusadome 1975a,b). Here, we present the interactions of $A$. thaliana with $M$. oryzae as a model pathosystem to dissect out plant resistance mechanisms in A. thaliana.

\section{RESULTS}

Interaction between $A$. thaliana and $M$. oryzae.

The hemibiotrophic ascomyceteous fungus $M$. oryzae, which belongs to the $M$. grisea species, includes the rice blast pathogen that has a devastating effect on rice (Oryza sativa). The blast fungus mechanically breaks the plant surface using an appressorium, a dome-shaped cell that generates massive turgor pressure. The appressorium produces a specialized hypha, a penetration peg, which pierces the plant surface (Koga 2001; Kankanala et al. 2007; Wilson and Talbot 2009). In this study, A. thaliana accessions were tested for their response to $M$. oryzae and interaction phenotypes were assessed at the cellular level (Fig. 1 and data not shown). Leaves of infected $A$. thaliana plants were harvested at 3 days postinoculation (dpi) and examined microscopically. Upon inoculation onto the Col0 accession of $A$. thaliana, conidia of $M$. oryzae germinated and formed appressoria at the tips of germ tubes. The majority (approximately 99.9\%) of conidia failed to penetrate leaf epidermal cells and fungal growth terminated during penetration attempts (Fig. 1E). No visible cellular responses, such as the HR-like cell death, occurred in the attacked epidermal cell (Fig. 1A and C). Thus, a block at the penetration step was the most prevalent form of resistance to $M$. oryzae in Col-0. In contrast, some $M$. oryzae conidia (approximately 5\%) penetrated into epidermal cells of the Ler accession of A. thaliana (Fig. 1E). The penetrated epidermal cells accumulated autofluorescent compounds, reported as being a reliable marker for the HR-like cell death (Koga 1994) (Fig. 1B and D). Thus, a block at the postpenetration step is also important for resistance to $M$. oryzae in A. thaliana. We also tested other A. thaliana accessions (Ksk-1, No-0, and RLD-1) for their response to $M$. oryzae. All the accessions tested exhibited a level of resis-
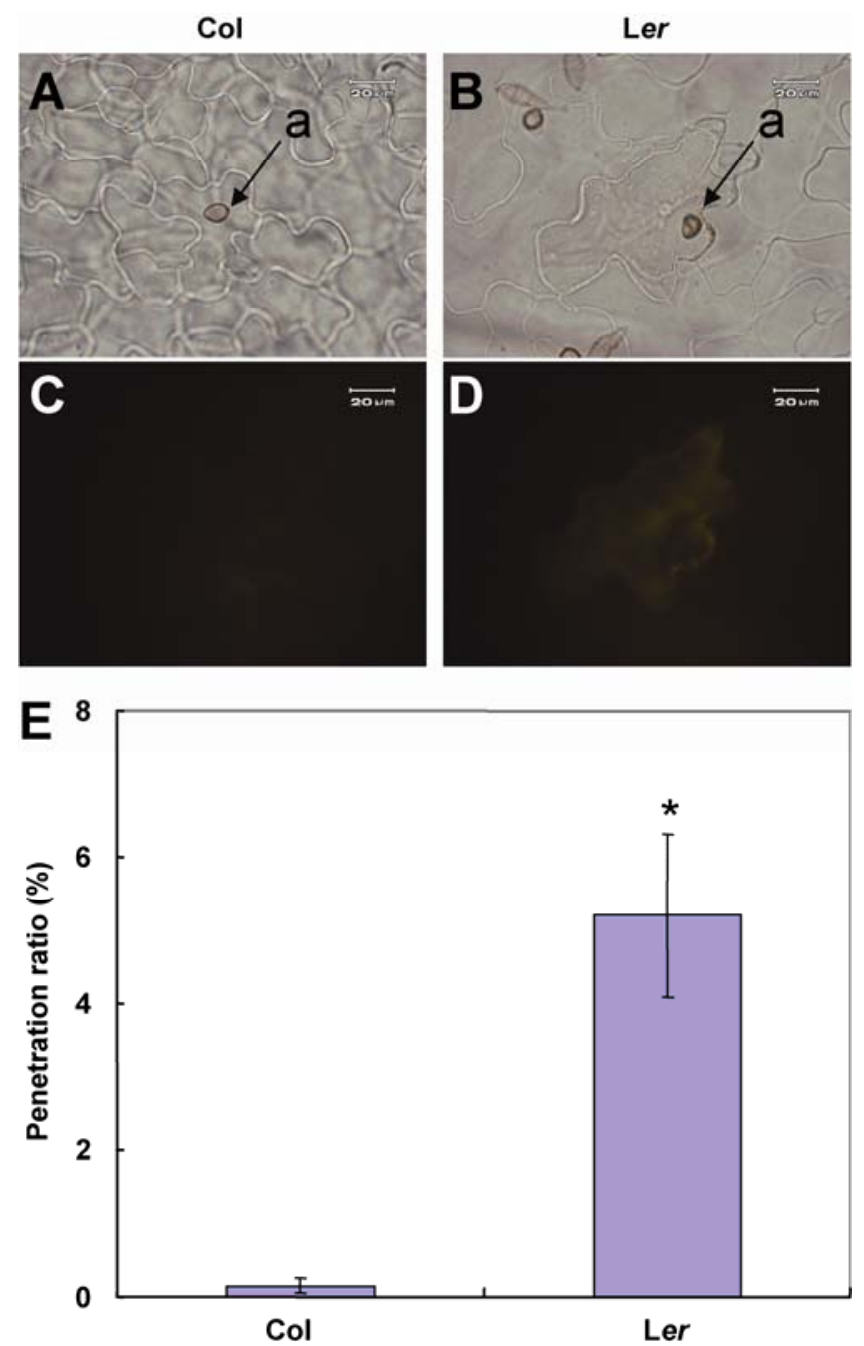

Fig. 1. Plant responses to attempted Magnaporthe oryzae infection. A and $\mathbf{B}$, Light microscopic view of infection sites of $\mathbf{A}$, Col-0 plants and $\mathbf{B}$, Ler plants at 3 days postinoculation (dpi); $\mathbf{a}=$ appressorium. $\mathbf{C}$ and $\mathbf{D}$, Epidermal cell-death-associated autofluorescence of $M$. oryzae-inoculated leaves of $\mathbf{C}$, Col-0 plants and D, Ler plants at 3 dpi was viewed by fluorescence microscopy. E, Mean of the frequency of M. oryzae penetration on Arabidopsis thaliana at $3 \mathrm{dpi}$, expressed as a percentage of total appressoria. Data were collected from six leaves from six independent plants of each accession. A minimum of 100 infection sties was inspected per leaf. Results represent the mean \pm standard error of three independent experiments. Asterisks indicate a significant difference from Col- $0(P<0.05$; Student's $t$ test). Bars $=20 \mu \mathrm{m}$. 
tance to penetration similar to that of the Col- 0 accession (data not shown). These findings support the idea that $M$. oryzae is a nonhost pathogen of $A$. thaliana.

\section{Identification of quantitative trait loci \\ for NHR in A. thaliana against $M$. oryzae.}

To examine the genetic basis of the variations in the responses of the different accessions of $A$. thaliana to $M$. oryzae, we used a well-established set of recombinant inbred lines (RIL), derived from a Col $\times$ Ler cross (Lister and Dean 1993). This resource facilitates the rapid evaluation of genetic variation and offers the ability to map any quantitative trait loci (QTL) controlling this variability (Ikka et al. 2007; Shafiei 2007). The Col/Ler RIL were tested for variation in their response to $M$. oryzae. Leaves of infected RIL were harvested at 3 dpi and examined microscopically. A population of 98 RIL was scored for resistance to penetration by $M$. oryzae. Using the composite interval mapping (CIM) method with QTL Cartographer software (Basten et al. 1994), we analyzed the QTL that controlled penetration resistance of the Col/Ler RIL against $M$. oryzae. Three QTL $(P<$ 0.05) were identified on chromosomes 1 and 2 (Fig. 2). QTL1 was positioned at 50.8 centimorgans $(\mathrm{cM})$ on chromosome 1 and had a logarithm of odds (LOD) score of 4.50, which accounted for $15.0 \%$ of the total variation for this trait. QTL2 was positioned at $40.4 \mathrm{cM}$ on chromosome 2 and had an LOD score of 4.32, which accounted for $14.0 \%$ of the total variation for this trait. QTL3 was positioned at $49.5 \mathrm{cM}$ on chromosome 2 and had an LOD score of 3.14, which accounted for $10.0 \%$ of the total variation for this trait. Collectively, these QTL for penetration resistance represented $39.0 \%$ of the total variation.

\section{Response of $A$. thaliana defense-related mutants to M. oryzae infection.}

To determine whether any of the known plant defense pathways affected the $A$. thaliana-M. oryzae interactions, the fol- lowing $A$. thaliana mutants and transgenic plants were inoculated with $M$. oryzae and monitored by microscopy: nprl-1 (Cao et al. 1994); sid2-1 (Nawrath and Metraux 1999); pad1-1, pad2-1, pad3-1, pad4-1, and pad5-1 (Glazebrook and Ausubel 1994); pmr1-1, prm2-1, pmr3-1, pmr4-1, pmr5-1, and pmr6-1 (Vogel and Somerville 2000); Atmlo2-7 (SALK_079850); eds1-2 (Ler) (Aarts et al. 1998); eds2-1, eds3-1, eds4-1, eds51, eds6-1, eds7-1, eds8-1, eds9-1, eds10-1, eds11-1, eds12-1, eds13-1, eds14-1, eds15-1, and eds16-1 (Glazebrook et al. 1996); ein2-1 (Alonso et al. 1999); coil-1 (Xie et al. 1998); jarl-1 (Staswick et al. 1992); gpal-4 and agbl-2 (Chen et al. 2006); rarl-21 (Tornero et al. 2002); edml-1 (Tor et al. 2002); nhol-1 (Lu et al. 2001); ndrl-1 (Century et al. 1995); and $N a h G$ (Lawton et al. 1995) (all Col-0 background except as noted). All these mutants exhibited a level of penetration resistance similar to that of the wild-type plants (data not shown), suggesting that none of these mutants significantly compromised resistance to $M$. oryzae.

Recently, the identification of $A$. thaliana mutants that are compromised in penetration resistance against the barley powdery mildew pathogen, B. graminis hordei, has led to significant insights into this mechanism. Mutations in PEN genes have highlighted possible roles for vesicle trafficking, antimicrobial compounds, and extracellular transport of small molecules in NHR against B. graminis hordei (Collins et al. 2003; Lipka et al. 2005; Kobae et al. 2006; Stein et al. 2006). We tested pen mutants (pen1, pen2, and pen3) in resistance against $M$. oryzae. Of these, only pen 2 had a significantly increased penetration ratio compared with the wild type (Fig. $3 \mathrm{~A})$. Upon inoculation onto pen 2 plants, $M$. oryzae conidia germinated and produced appressoria which attempted penetration of the epidermal cell in an infection process similar to that which occurs on its host (rice) (Koga 2001). Some of them could penetrate leaf epidermal cells. This led to the accumulation of autofluorescent compounds, callose, and $\mathrm{H}_{2} \mathrm{O}_{2}$ in the

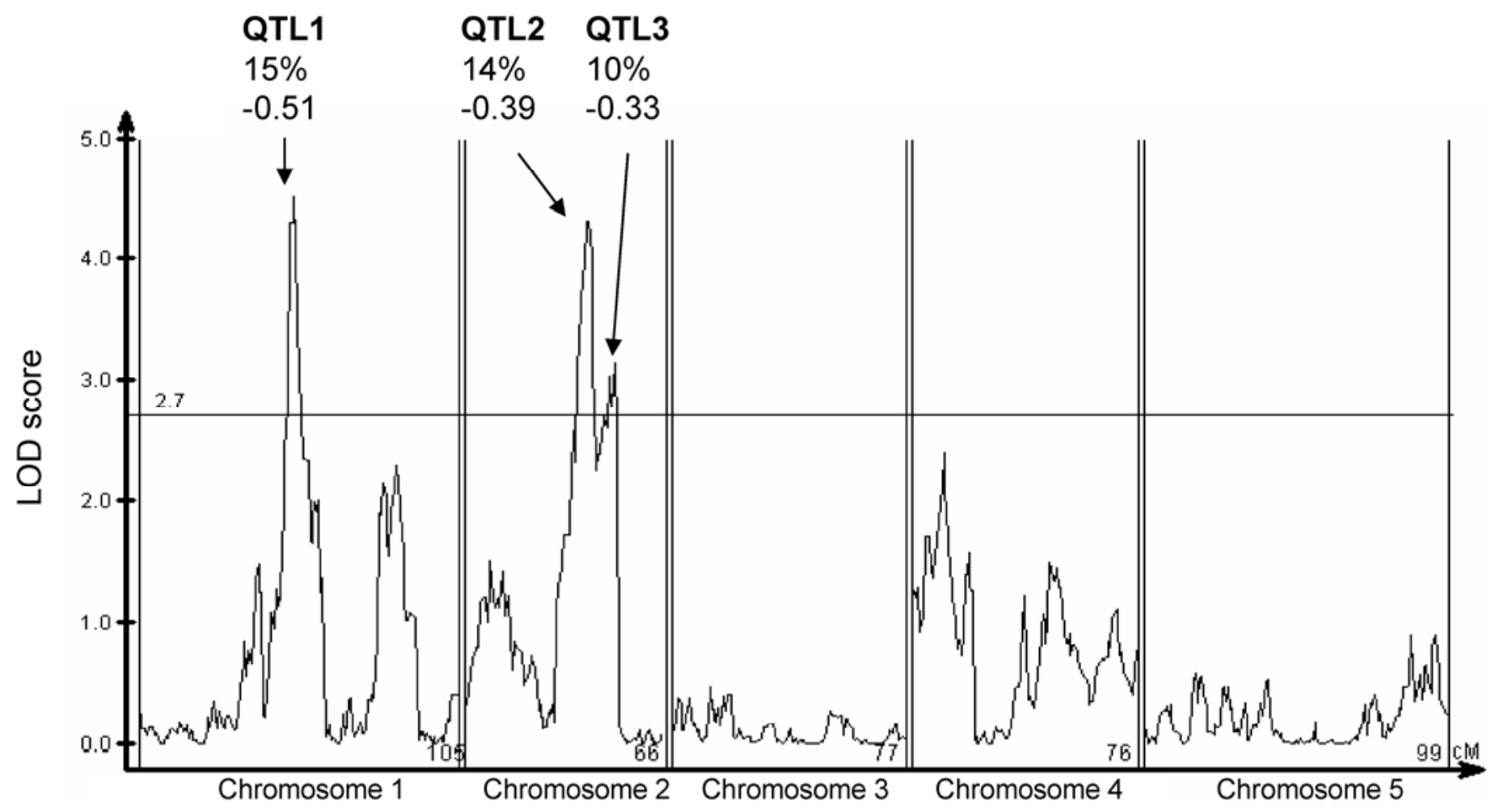

Fig. 2. Logarithm of odds (LOD) score profile for preinvasion resistance in a Col/Ler recombinant inbred line population. LOD score curves are shown on the vertical scales and horizontal axes show map distances in centimorgans. Chromosome numbers are indicated in the panel. The 2.7 LOD threshold used for quantitative trait locus (QTL) detection is shown as a horizontal line. Percentage of the total phenotypic variance explained and the allele additive effect of each QTL is shown. A negative or positive sign for additive effect indicates that the given QTL was derived from either the Col or the Ler accession, respectively. 
challenged epidermal cell, which preceded the HR-like cell death (Fig. 3B through F). In the interaction, some fungi formed intracellular infection hyphae but fungal growth terminated during elongation attempts (Fig. 3G). M. oryzae infection did not progress beyond this stage. Thus, loss of PEN2 function does not allow $M$. oryzae to complete its life cycle and form asexual conidia on A. thaliana as it does on rice, suggesting that additional factors contribute to NHR to $M$. oryzae in A. thaliana.

\section{Double-mutant analysis to evaluate the role of defense signaling pathways in the NHR to M. oryzae.}

The results described above support a crucial role for PEN2 in controlling the penetration resistance of $A$. thaliana to $M$. oryzae. As a next step, double mutants were generated between pen 2 and defense-related mutants or transgenic plants to evaluate the role of well-described defense signaling pathways in the resistance to $M$. oryzae in a pen 2 background. Leaves of infected A. thaliana plants were harvested at 3 dpi and examined microscopically. First, we investigated double mutants affecting the SA pathway (pen2 pad4, pen2 eds5, pen2 sid2, and pen $2 \mathrm{NahG}$ ). Among them, only pen $2 \mathrm{NahG}$ plants showed significant increases in penetration ratio relative to pen2 plants (Fig 4). NahG-expressing plants convert SA to catechol. The SA biosynthetic mutant sid2 did not affect a penetration phenotype of pen2; therefore, partial loss of penetration resistance might be due to NahG-dependent catechol production. However, no significant difference in penetration was detected between pen 2 and pen 2 treated with catechol (data not shown). Second, we investigated double mutants affecting the JA/ET pathway (pen2 jar1, pen2 coil, and pen2 ein2). Although pen2 jar1 and pen2 coil plants allowed slightly increased frequency of penetration, none of these double mutants showed significant increases in penetration ratio (Fig. 5) compared with pen 2 plants. These results suggest that neither the SA nor the JA/ET signal transduction pathways contribute significantly to penetration resistance to $M$. oryzae in A. thaliana. Third, we investigated double mutants affected in $\mathrm{G}$ protein signaling (pen 2 gpal and pen 2 agbl). Although pen2 gpal plants tended to have decreased penetration ratio compared with pen 2 plants, pen 2 agbl plants had a significantly increased penetration ratio compared with pen 2 plants, suggesting involvement of AGB1 in the penetration resistance (Fig. 5). In pen $2 \mathrm{NahG}$ and pen 2 agbl plants, $M$. oryzae penetrated the epidermal cell but did not grow further, either interof intracellularly, into neighboring cells (data not shown).

\section{Double mutant analysis to evaluate the role of PMR genes on NHR to M. oryzae.}

A. thaliana pmr mutants are loss-of-function mutants that provide enhanced disease resistance to the powdery mildew, $G$.

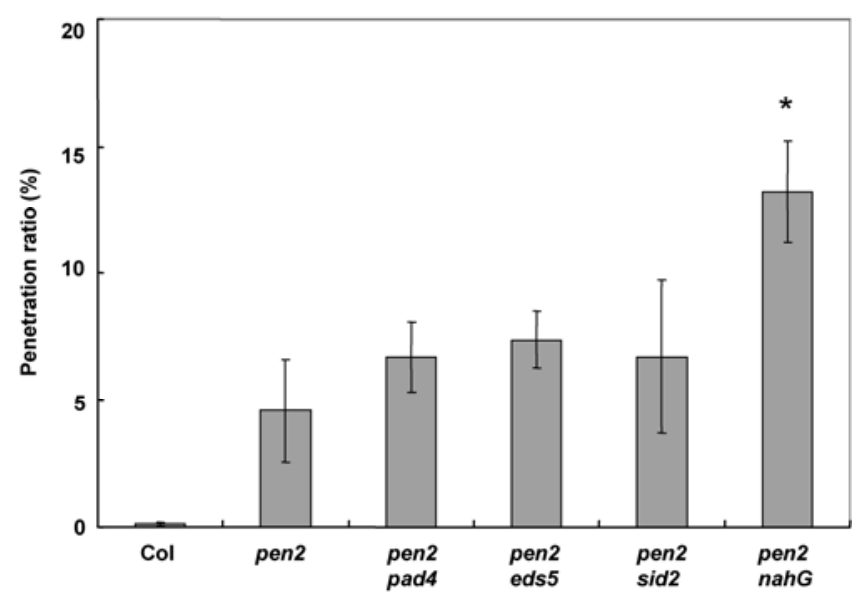

Fig. 4. Double mutant analysis to evaluate the role of the salicylic acid (SA) signal transduction pathway on resistance to Magnaporthe oryzae in Arabidopsis thaliana. Quantitative analysis of cell entry on SA signal transduction mutants in a penetration (pen)2 background. Mean of the frequency of $M$. oryzae penetration on double mutants at 3 days postinoculation was expressed as a percentage of total appressoria. Data were collected from six leaves from six independent plants per line. A minimum of 100 infection sties was inspected per leaf. Results represent mean \pm standard error of three independent experiments. Asterisks indicate a significant difference from pen2 $(P<0.05$; Student's $t$ test).
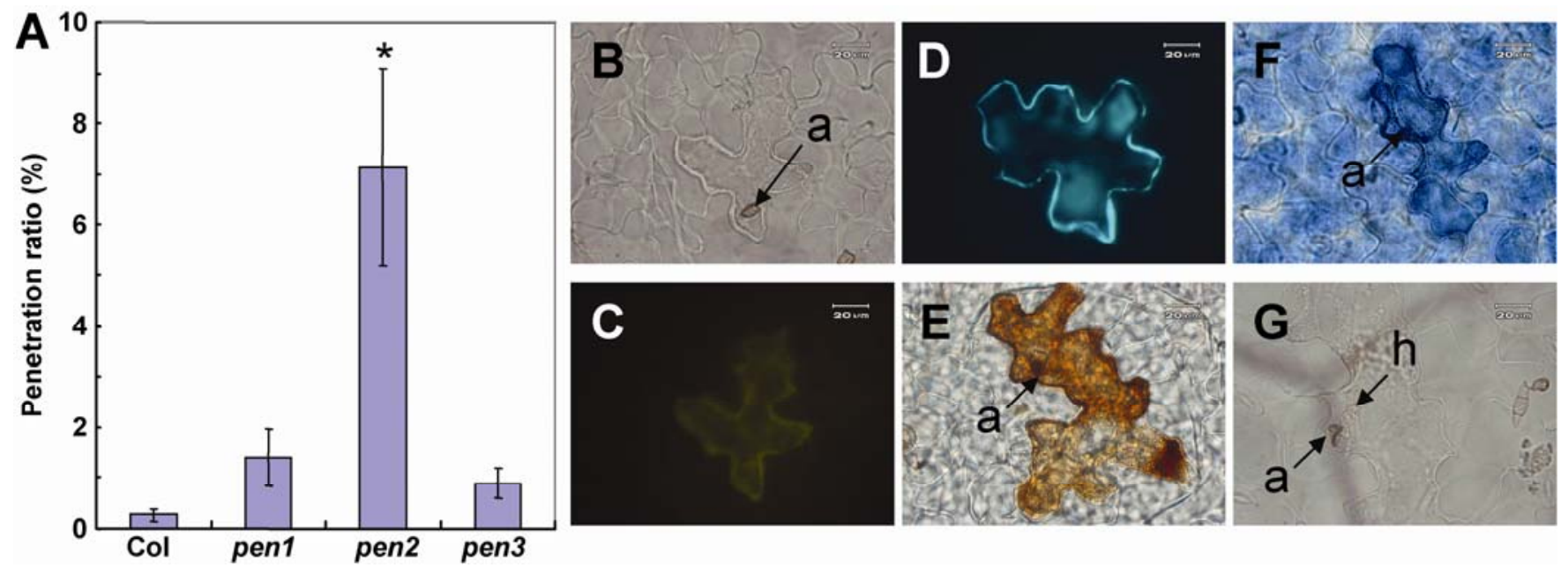

Fig. 3. penetration (pen)2 resistance phenotypes. A, Quantitative analysis of cell entry on pen mutants. Mean of the frequency of Magnaporthe oryzae penetration on pen mutants at 3 days postinoculation (dpi) was expressed as a percentage of total appressoria. Data were collected from six leaves from six independent plants per line. A minimum of 100 infection sties was inspected per leaf. Results represent the mean \pm standard error of three independent experiments. Asterisks indicate a significant difference from Col- $0(P<0.05$; Student's $t$ test $)$. B, Light microscopic view of infection sites of pen 2 plants at 3 dpi; $\mathrm{a}=$ appressorium. C, Epidermal cell-death-associated autofluorescence at infection site of pen 2 plants at 3 dpi was viewed by fluorescence microscopy. D, Callose deposition at infection site of pen 2 plants at 3 dpi was visualized by fluorescence microscopy following aniline blue staining. $\mathbf{E}, \mathrm{H}_{2} \mathrm{O}_{2}$ accumulation at infection site of pen 2 plants at 3 dpi was monitored by 3,3-diaminobenzideine tetrahydrochloride staining by bright-field microscopy; $\mathrm{a}=\mathrm{appressorium}$. $\mathbf{F}$. Cell death at infection site of pen 2 plants at 3 dpi was visualized by trypan blue staining by bright-field microscopy; a = appressorium. G. Intracellular infection hyphae inside infected epidermal cell of pen 2 plants at $3 \mathrm{dpi}$; $\mathrm{a}=$ appressorium and $\mathrm{h}=$ hyphae. Bars $=20 \mu \mathrm{m}$. 
cichoracearum (Vogel and Somerville 2000). PMR2 is allelic to MLO2 (Consonni et al. 2006), PMR4 encodes a wound- and pathogen-associated callose synthase (Jacobs et al. 2003; Nishimura et al. 2003), PMR5 belongs to a large family of plant-specific genes of unknown function (Vogel et al. 2004), and PMR6 encodes a GPI-anchored pectate-lyase-like protein (Vogel et al. 2002). However, their contribution to NHR is poorly understood. Because the single $p m r$ mutations did not affect the penetration resistance to $M$. oryzae (data not shown), double mutants were generated between pen 2 and $p m r$ mutants to determine whether these factors were necessary for the resistance to $M$. oryzae in a pen 2 background. Leaves of infected A. thaliana plants were harvested at $3 \mathrm{dpi}$ and examined microscopically. Only pen 2 pmr 5 plants showed significant increases in penetration ratio compared with pen 2 plants (Fig. 6). This indicates that PMR5 has a function in preinvasion resistance against $M$. oryzae. In pen 2 pmr 5 plants, $M$. oryzae penetrated the epidermal cell but did not grow further as in the case of pen $2 \mathrm{NahG}$ and pen $2 \mathrm{agbl}$ plants (data not shown).

We also investigated callose formation, including papillaryassociated callose and whole-cell callose, in pen $2 \mathrm{pmr}$ epidermal cells upon inoculation with $M$. oryzae by aniline blue staining. Papillary-associated callose formation beneath fungal appressoria is a widespread plant response in their interaction with diverse fungal parasites, and whole-cell callose is a marker for the HR-like cell death (Koga 1994; Jacobs et al. 2003; Nishimura et al. 2003). UV-induced fluorescence with aniline blue was readily detectable in plant cells beneath $M$. oryzae appressoria (papillary-associated callose) (Fig. 7A through L) and invaded epidermal cells (whole-cell callose) (Fig. 7M through X). The papillary-associated callose production beneath $M$. oryzae appressoria in wild-type plants suggests that $A$. thaliana epidermal cells detect and respond to entry attempts of the fungus. However, whole-cell callose formation was detected only in the pen 2 background, except for pen 2 pmr4, suggesting that penetration of the fungus in the cells is required for the production of callose. Because pmr4 is specifically impaired in the accumulation of callose, fluorescence was very weak in the pen 2 pmr4 double mutant compared with pen 2 plants (Fig. $7 \mathrm{H}$ and T). Furthermore, the callose accumulation in pen 2 pmr 5 plants was the same as in pen 2 plants (Fig. $7 \mathrm{~J}$ and V). These results

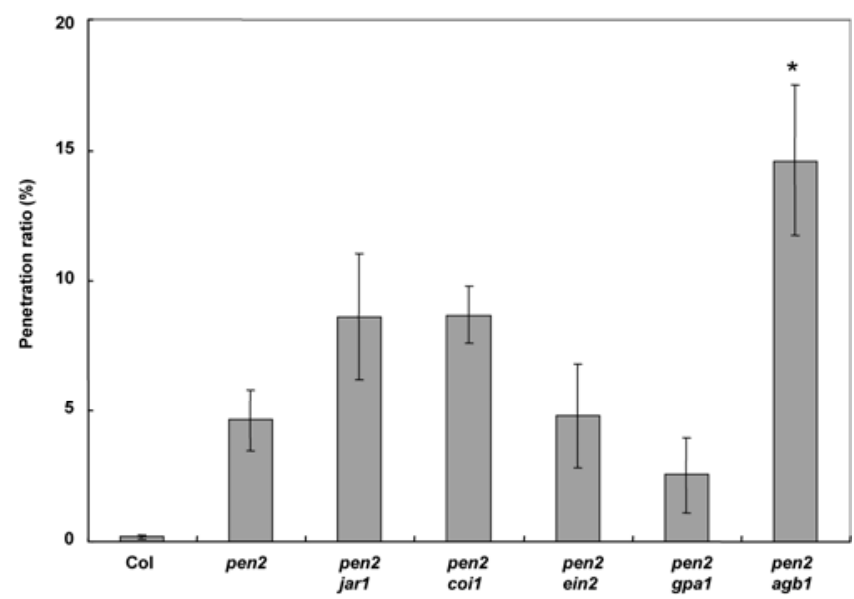

Fig. 5. Double mutant analysis to evaluate the role of the jasmonate and ethylene signal transduction pathway and heterotrimeric $\mathrm{G}$ protein on resistance to Magnaporthe oryzae in Arabidopsis thaliana. The frequency of $M$. oryzae penetration on double mutants at 3 days postinoculation was expressed as a percentage of total appressoria. Data were collected from six leaves from six independent plants per line. A minimum of 100 infection sties was inspected per leaf. Results represent mean \pm standard error of three independent experiments. Asterisks indicate a significant difference from pen $2(P<0.05$; Student's $t$ test $)$. suggest that callose accumulation is dispensable for pre- and postinvasion resistance to $M$. oryzae in A. thaliana.

\section{DISCUSSION}

Among pen mutants, only the pen 2 mutant allowed increased penetration into epidermal cells by the nonadapted pathogen M. oryzae. This indicates that the effect of pen 2 is broader than that of penl (which affects only B. graminis hordei infection), as described previously (Lipka et al. 2005). We have also shown that NahG, AGB1, and PMR5 contribute to the PEN2mediated preinvasion resistance in the A. thaliana-M. oryzae interactions, suggesting a complex genetic network regulating the resistance.

Analysis of a series of well-characterized defense-response mutants following $M$. oryzae challenge revealed that none of these lines was significantly more susceptible to $M$. oryzae than the wild type (data not shown). Thus, the signaling pathways in which these mutants are affected, including SA- and JA/ET-dependent pathways, are likely either to function redundantly or to be dispensable for resistance against $M$. oryzae.

In interactions with nonadapted powdery mildews, PEN1 is recruited in the plasma membrane microdomain beneath the powdery mildew appressoria (Collins et al. 2003). Cell-wall appositions formation (papillae) is delayed in response to attempted powdery mildew entry in pen 1 plants, and this correlates with impaired preinvasion resistance (Collins et al. 2003; Assaad et al. 2004). However, M. oryzae failed to invade epidermal cells of pen1 plants (Fig. 3). Although ROR2 is the functional homolog of $A$. thaliana PEN1 and is required for mlo-mediated broad-spectrum resistance against all tested host barley powdery mildew isolates (Collins et al. 2003), ROR2 is not essential for resistance against strains of the rice blast fungus $M$. oryzae that can infect barley (Jarosch et al. 2005). Thus, these data suggest that PEN1/ROR2 may not exert an entry-limiting function in preinvasion resistance to Magnaporthe spp. in plants.

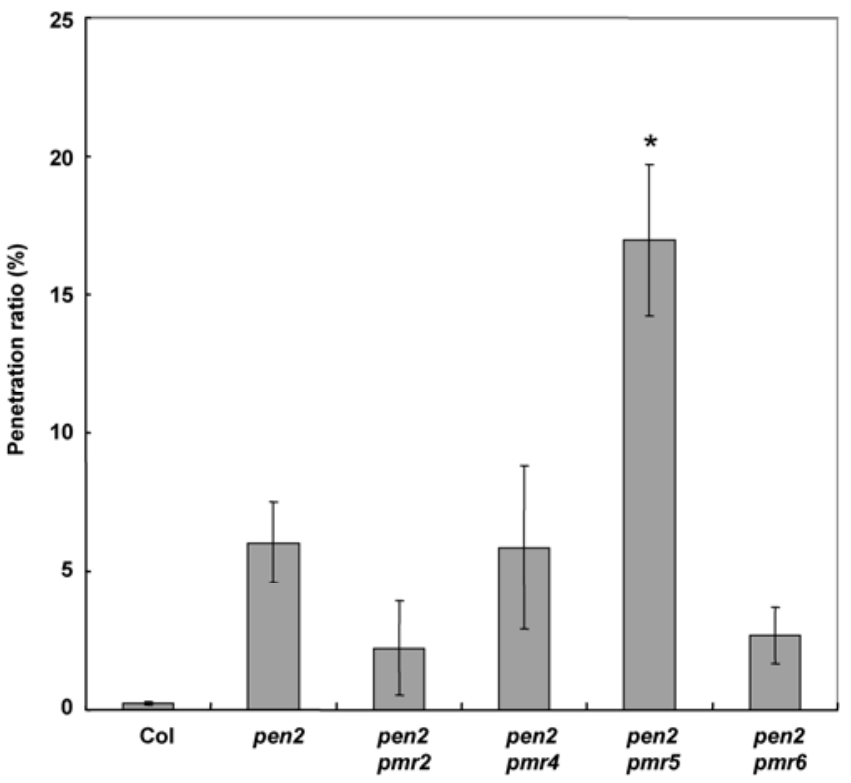

Fig. 6. Double mutant analysis to evaluate the role of the powdery mildew resistant (PMR) genes on resistance to Magnaporthe oryzae in Arabidopsis thaliana. The frequency of $M$. oryzae penetration on double mutants at 3 days postinoculation was expressed as a percentage of total appressoria. Data were collected from six leaves from six independent plants per line. A minimum of 100 infection sties was inspected per leaf. Results represent mean \pm standard error of three independent experiments. Asterisks indicate a significant difference from pen $2(P<0.05$; Student's $t$ test $)$. 
Stein and associates (2006) have proposed a model for the role of PEN3 in penetration resistance in which PEN2 converts a nontoxic substrate to a toxic product, which is then exported either directly or after further modification to the apoplast by PEN3, poisoning the fungal penetration peg as it attempts to cross the cell wall. In this model, PEN3 exports toxic secondary metabolites to the apoplast at sites of attempted invasion and the myrosinase PEN2 activates one of these toxins by hydrolysis of a nontoxic precursor metabolite. Because preinvasion resistance to $M$. oryzae is PEN2 dependent but PEN3 independent (Fig. 3A), PEN2 might activate other toxins by hydrolysis of other precursor metabolites, and an ABC transporter protein other than PEN3 might export it to the apoplast in the $A$. thaliana-M. oryzae interactions.

Although NHR to M. oryzae was not compromised in NahG transgenic plants (data not shown), pen $2 \mathrm{NahG}$ plants allowed increased entry into epidermal cells by $M$. oryzae compared with pen2 plants (Fig. 4). Because pen2 sid2 plants did not provide evidence of the involvement of the SA pathway in NHR (Fig. 4), it is likely that SA-independent responses mediated by NahG contribute to NHR. Although NahG affects the functioning of the SA pathway, it also exerts an SA-independent, yet-to-be-characterized effect on resistance (Van Wees and Glazebrook 2003). NahG-expressing plants convert SA to catechol; therefore, partial loss of penetration resistance might be due to NahG-dependent catechol production (Van Wees and Glazebrook 2003). In fact, NahG-dependent catechol production affects Atmlo2 resistance against powdery mildew in Atmlo2 $N a h G$ plants (Consonni et al. 2006). However, no significant difference in penetration following $M$. oryzae challenge was detected between pen 2 and pen 2 treated with catechol (data not shown). Thus, enhanced $M$. oryzae epidermal cell entry in pen2 $N a h G$ plants is likely due to non-SA-dependent responses associated with $N a h G$ expression but not catechol production. SA-independent effects of $N a h G$ have been reported previously (Heck et al. 2003; Brodersen et al. 2005; Zhang 2008).
The pmr mutants were isolated in a screen to recover lossof-susceptibility to $G$. cichoracearum mutants in A. thaliana, and some of the genes have been cloned. PMR2 encodes an ortholog of the barley MILDEW LOCUS O (MLO), MLO2 (Consonni et al. 2006). Both barley MLO and A. thaliana PMR2 (MLO2) serve as functionally conserved negative regulators of entry resistance to adapted obligate biotrophic powdery mildews (Buschges et al. 1997; Consonni et al. 2006). Interestingly, loss of MLO reduces preinvasion resistance to $M$. oryzae in barley (Jarosch et al. 2003). In contrast, neither pmr2 (mlo2) plants nor pen 2 pmr 2 plants were compromised in preinvasion resistance in A. thaliana-M. oryzae interactions (Fig. 6 and data not shown). This suggests that PMR2 (MLO2) has no function in preinvasion resistance in $A$. thaliana-M. oryzae interactions. However, in A. thaliana-powdery mildew interactions, PMR2 (MLO2) controls resistance together with the phylogenetically closely related paralogs MLO6 and MLO12, which act in partial functional redundancy (Consonni et al. 2006). Thus, it remains possible that a single pmr2 (mlo2) mutation might not be sufficient to compromise the preinvasion resistance to $M$. oryzae in A. thaliana.

PMR4 controls callose synthesis at cell wall appositions (papillae) that form beneath infection and wound sites and are believed to provide a physical barrier to fungal penetration (Jacobs et al. 2003; Nishimura et al. 2003). In A. thaliana-M. oryzae interactions, callose accumulation, including papillary callose and whole-cell callose, occurred in attacked epidermal cells (Fig. 7), indicating that epidermal cells detect and respond to entry attempts by the fungus in both preinvasion and postinvasion resistance. In pen 2 pmr4 plants, although callose accumulation in the epidermal cells, including papillary callose and whole-cell callose, was significantly reduced, they still showed pre- and postinvasion resistance against $M$. oryzae (Fig. 6), suggesting that PMR4-dependent callose accumulation does not contribute to resistance to $M$. oryzae in A. thaliana.
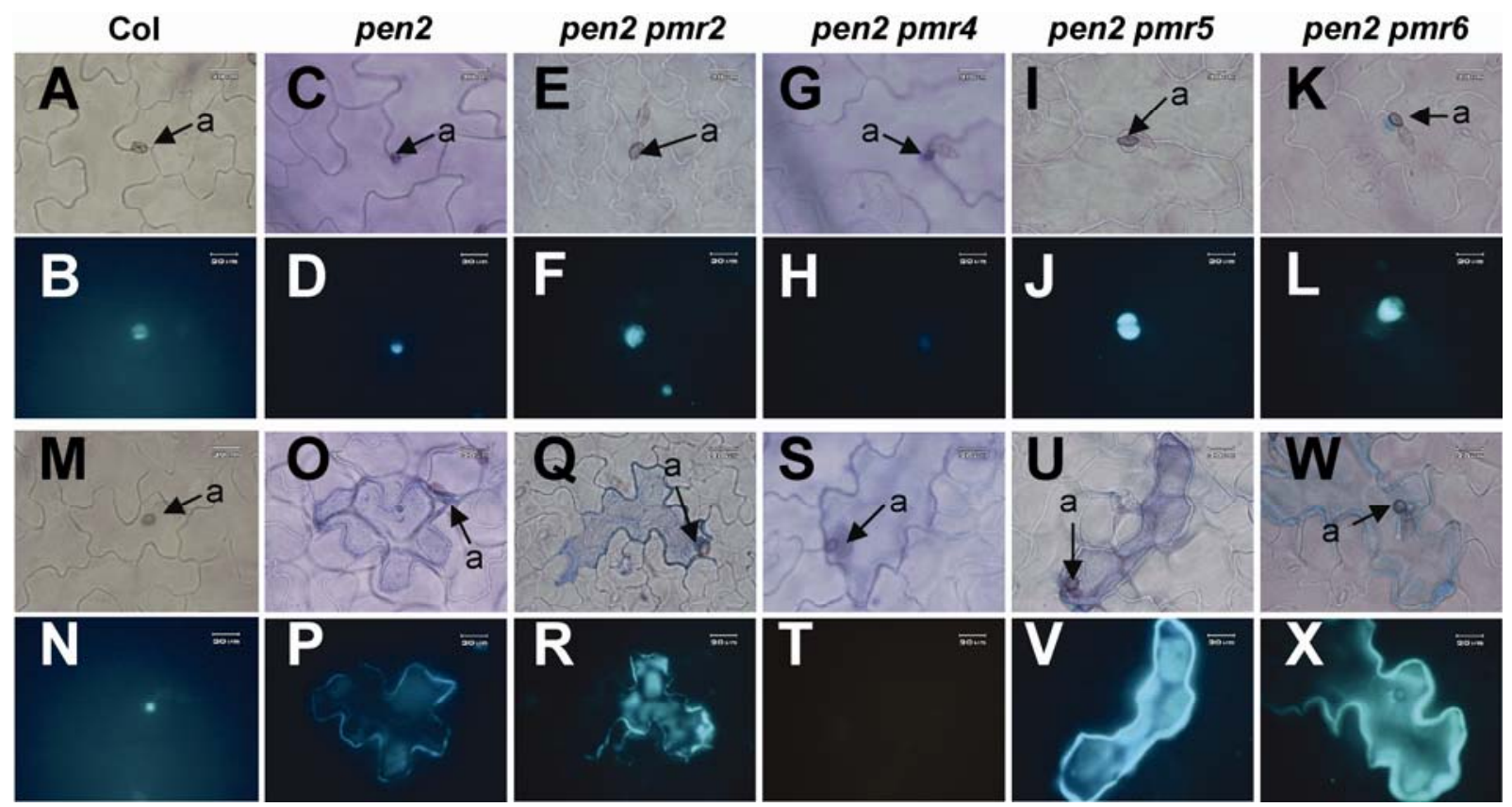

Fig. 7. Accumulation of callose at infection sites in double mutants. A through L, Papillary callose deposition at attempted penetration sites. Lightmicroscopic view of infection sites of $\mathbf{A}$, Col-0; C, pen2; E, pen2 pmr2 (Atmlo2-7); G, pen2 pmr4; I, pen2 pmr5; and K, pen2 pmr6 plants at 3 days postinoculation (dpi). Papillary callose deposition at penetration sites of $\mathbf{B}$, Col-0; D, pen2; F, pen2 pmr2 (Atmlo2-7); H, pen2 pmr4; J, pen2 pmr5; and L, pen 2 pmr6 plants at 3 dpi were visualized by fluorescence microscopy following aniline blue staining. $\mathbf{M}$ through $\mathbf{X}$, Callose deposition in whole epidermal cell. Light-microscopic view of infection sites of $\mathbf{M}$, Col-0; $\mathbf{O}$, pen2; $\mathbf{Q}$, pen2 pmr2 (Atmlo2-7); S, pen2 pmr4; U, pen2 pmr5; and W, pen2 pmr6 plants at 3 dpi. Callose deposition at infection sites of $\mathbf{N}$, Col-0; P, pen2; R, pen2 pmr2 (Atmlo2-7); T, pen2 pmr4; V, pen2 pmr5; and X, pen2 pmr6 plants at 3 dpi were visualized by fluorescence microscopy following aniline blue staining; $\mathrm{a}=$ appressorium. Bars $=20 \mu \mathrm{m}$. 
PMR5 encodes a member of a large family of plant-specific proteins of unknown function that is likely targeted to the endoplasmic reticulum and secretory pathway (Vogel et al. 2004). PMR6 encodes a putative pectate lyase with proposed pectin-degrading activity localized at the cell wall (Vogel et al. 2002). Because the pmr5 pmr6 double mutants show further increased resistance to powdery mildew compared with the respective single mutants, it seems likely that the two genes control parallel and independent defense responses (Vogel et al. 2004). Although pen 2 pmr5 plants showed significant increases in penetration ratio compared with pen 2 plants, pen 2 pmr6 plants did not show such an increase in A. thaliana-M. oryzae interactions (Fig. 6), suggesting that only PMR5 acts in preinvasion resistance to $M$. oryzae in a pen 2 background.

The heterotrimeric $\mathrm{G}$ protein is known to play a key role in stress responses as well as in development (Temple and Jones 2007). In A. thaliana-M. oryzae interactions, although pen 2 gpal plants tended to have a decreased penetration ratio compared with pen 2 plants, pen 2 agbl plants had a significantly increased penetration ratio compared with pen 2 plants (Fig. 5). If G-protein-mediated signaling in A. thaliana follows the mechanism of action established in animal systems, loss of function of $\mathrm{G} \alpha$ could cause the release of free $\mathrm{G} \beta \gamma$, which leads to the activation of G $\beta \gamma$ signaling (Temple and Jones 2007). Our result supports this hypothesis and suggests that AGB1 is involved in the preinvasion resistance as a positive regulator and does not depend on the formation of a canonical G $\alpha \beta \gamma$ heterotrimer.

We have shown that a block at the penetration step was the most prevalent form of resistance to $M$. oryzae in Col- 0 and that the preinvasion resistance of Col-0 is stronger than that of Ler (Fig. 1). To examine the genetic basis underlying the natural variation in the responses of $A$. thaliana to $M$. oryzae, we utilized a well-established set of RIL, derived from a Col $\times$ Ler cross (Lister and Dean 1993). This analysis identified three QTL that govern resistance against $M$. oryzae. These QTL represented $39.0 \%$ of the total variation for this trait, suggesting that there are unidentified polymorphic loci controlling preinvasion resistance in A. thaliana (Fig. 2). We checked the identity of the genes in the identified QTL. The three QTL associated with this trait do not contain PEN2, PMR5, and $A G B 1$, suggesting that a $P E N 2$-independent pathway controls preinvasion resistance in A. thaliana. However, the QTL2 on chromosome 2 contained a GPA1 (At2g26300) coding sequence. In fact, the pen 2 gpal plants tended to have a decreased penetration ratio compared with pen 2 plants (Fig. 5), suggesting that GPA1 might function as a negative regulator in the preinvasion resistance. This supports the hypothesis that $\mathrm{G} \alpha$ sequesters $G \beta \gamma$, which leads to the inactivation of $G \beta \gamma$ signaling. Although the amino acid sequences deduced from the GPAl genes is the same in Col-0 and Ler, there might be a difference in levels of expression of GPA1 between Col-0 and Ler, which might affect G $\beta \gamma$ signaling. QTL2 also contained an ERECTA (At2g26330) coding sequence. ERECTA has been identified as a positive mediator of resistance against necrotrophic infestation by both bacteria (Ralstonia solanacearum) (Godiard et al. 2003) and fungi (Plectosphaerella cucumerina and Pythium irregulare) (Llorente et al. 2005; Adie et al. 2007; Van Zanten et al. 2009). Interestingly, PEN2 is involved in the resistance in A. thaliana-P. irregulare interactions (Adie et al. 2007) and AGB1 is involved in the resistance in A. thaliana-Plectosphaerella cucumerina interactions (Llorente et al. 2005). Furthermore, analysis of agbl er double mutants suggested that AGB1 may function in an ER developmental pathway regulating silique width (Lease et al. 2001). These results suggest that PEN2, AGB1, and ERECTA coordinately regulate the resistance to pathogens in A. thaliana. Further studies would be re- quired to define more accurately the regions of the genome in which candidate genes are located. Identification of the polymorphisms underpinning these QTL would provide significant new insight into the expression of preinvasion resistance.

As shown in this study, pen 2 mutants allowed increased penetration of $M$. oryzae, which leads to an HR-like cell death (Fig. 3F). This indicates that $A$. thaliana NHR to $M$. oryzae is based upon two successive, multicomponent, and independently effective defense layers: PEN2-mediated preinvasion resistance and postinvasion resistance. It has been shown that PAD4 is involved in the postinvasion resistance to nonadapted powdery mildew in A. thaliana (Lipka et al. 2005). In the work reported here, the effects of $N a h G$, agbl, and pmr5 become visible only in a pen 2 genetic background, suggesting that $N a h G, A G B 1$, and PMR5 might be involved in postinvasion resistance. However, none of the pen 2 double mutants, including pen 2 pad4, supported growth of fungal colonies or sporulation (data not shown), indicating that postinvasion resistance is functional in these double mutants. Thus, PAD4 is not involved in postinvasion resistance in $A$. thaliana-M. oryzae interactions and NahG, $A G B 1$, and PMR5 contribute only to PEN2-mediated preinvasion resistance, indicating a role of unidentified genes in controlling postinvasion resistance to $M$. oryzae in A. thaliana. Alternatively, it could be that essential requirements that are needed to establish the infection are missing in A. thaliana.

Recently, Park and associates (2009) reported that some $M$. oryzae strains were able to infect $A$. thaliana. They also showed that the ability to produce melanized functional appressoria was not an absolute requirement for the infection of $A$. thaliana and that fungal metabolites were important determinants of the pathogenicity of $M$. oryzae. These data contrast with our studies. This discrepancy might be due to the difference of $M$. oryzae strains and experimental conditions used in the experiments. Future studies will be required to reveal the genetic and mechanistic requirements for NHR in A. thaliana$M$. oryzae interactions. These studies may eventually be useful to improve resistance in rice.

\section{MATERIALS AND METHODS}

\section{Plant material.}

A. thaliana plants were grown under short-day conditions (9 $\mathrm{h}$ of light) at $22^{\circ} \mathrm{C}$ in a growth room. The following mutants and transgenic plants were used in this study: pen 1-1 (Collins et al. 2003); pen2-1 (Lipka et al. 2005); pen3 (pdr8-1) (Kobae et al. 2006); Atmlo2-7 (SALK_079850); nprl-1 (Cao et al. 1994); sid2-1 (Nawrath and Metraux 1999); pad1-1, pad2-1, pad3-1, pad4-1, and pad5-1 (Glazebrook and Ausubel 1994); pmr1-1, prm2-1, pmr3-1, pmr4-1, pmr5-1, and pmr6-1 (Vogel and Somerville 2000); eds1-2 (Ler) (Aarts et al. 1998); eds2-1, eds3-1, eds4-1, eds5-1, eds6-1, eds7-1, eds8-1, eds9-1, eds101, eds11-1, eds12-1, eds13-1, eds14-1, eds15-1, and eds16-1 (Glazebrook et al. 1996); ein2-1 (Alonso et al. 1999); coil-1 (Xie et al. 1998); jarl-1 (Staswick et al. 1992), gpal-4 and agbl-2 (Chen et al. 2006); rarl-21 (Tornero et al. 2002); edm1-1 (Tor et al. 2002); nhol-1 (Lu et al. 2001); ndr11(Century et al. 1995); and NahG (Lawton et al. 1995) (all Col-0 background except as noted). Among these, pad4-1, eds5-1, sid2-1, NahG, coil-1, jar1-1, ein2-1, pmr4-1, pmr5-1, pmr6-1, and Atmlo2-7(pmr2) were used for intermutant crosses with pen2-1. Respective double homozygous F2 progeny were identified by polymerase chain reaction (PCR) using suitable cleaved amplified polymorphic sequence (CAPS) or derived CAPS markers; genotypes were verified in the subsequent $(\mathrm{F} 3)$ generation. The $A$. thaliana accessions tested in this study were Col-0, Ler, Ksk-1, No-0, and RLD-1. 
For QTL analysis, the recombinant inbred (RI) population was obtained from the Arabidopsis Biological Resource Center. A subset of the RI populations (98 lines) was used for QTL analysis. Three plants for each RIL were grown and assayed for penetration resistance.

\section{Fungal material.}

The $M$. oryzae isolate Kita 1 (race 007) was incubated on oatmeal agar media in petri dishes at $25^{\circ} \mathrm{C}$ and the inoculum was prepared as described previously (Koga and Nakayachi 2004). For $M$. oryzae inoculations, $15-\mu 1$ droplets $\left(10^{4}\right.$ spores per milliliter) were applied to leaves of 4- to 5-week-old plants and plants were kept in conditions with saturating humidity until harvested.

\section{Cytology and quantification of fungal growth.}

For quantification of cell entry, the proportion of germinated fungal sporelings that developed appressorium was assessed on six leaves from six independent plants per experiment and genotype (minimum of 100 appressoria per leaf evaluated). Fungal penetration success on each genotype was quantified in at least three independent experiments. Plants were inoculated with $M$. oryzae and examined by fluorescence microscopy to monitor the autofluorescence resulting from the HR-like cell death triggered by penetration. For visualization of callose, samples were stained with aniline blue as described previously (Ishikawa et al. 2001). To assay for $\mathrm{H}_{2} \mathrm{O}_{2}$ accumulation, samples were stained with 3,3-diaminobenzidine tetrahydrochloride as described previously (Ishikawa et al. 2001). To visualize the epidermal cell death, the leaves were stained with lactophenol trypan blue and cleared with saturated chloral hydrate as described previously (Ishikawa et al. 2001).

\section{Treatment with catechol.}

To test for the effect of catechol on penetration resistance, 1 $\mu \mathrm{M}$ pyrocatechol or deionized water (mock) was applied to leaves $6 \mathrm{~h}$ prior to inoculation with $M$. oryzae as described previously (Consonni et al. 2006).

\section{QTL analysis.}

In all, 676 genetic markers were used for Col/Ler RI populations as described previously (Singer et al. 2006). Using penetration ratio as a resistance index, composite interval mapping was carried out using QTL Cartographer, Model 6 (ver. 2.5) (Basten 1994). To reject false positives, a threshold of the LOD score for CIM analysis was calculated by a permutation test as described previously (Churchill and Doerge 1994) (1,000 times permutation at the significant level of $\alpha=0.05$ ). The $R^{2}$ values were calculated by the program.

\section{Statistical analysis.}

Statistical analysis of data in this study is based on $t$ test. Calculations were performed on a minimum of three data sets $(n=3)$, assuming two-sample equal variance and a two-tailed distribution. In the context of this report, we considered $P<$ 0.05 to be a significant result.

\section{ACKNOWLEDGMENTS}

We acknowledge the Arabidopsis Biological Resource Center for providing the collection of $A$. thaliana accessions, RIL population, and mutants. We thank H. Koga (Ishikawa Prefectural University) for providing the M. oryzae isolate, P. Schulze-Lefert (Max Planck Institute for Plant Breeding Research) for seed of pen1-1 and pen2-1, J. Turner (University of East Anglia) for coil-1, Syngenta for NahG, C. Nawrath (University of Lausanne) for sid2-1, J. Vogel (United States Department of Agriculture) for pmr5-1, J. Dangl (University of North Carolina) for rar1-21, M. Tör (Horticulture Research International) for edm1-1, F. Ausubel (Massachu- setts General Hospital) for eds2-1 through eds16-1, J. Parker (The Sainsbury Laboratory) for eds 1-2, J.-M. Zhou (Kansas State University) for nhol-1, B. Staskawicz (University of California) for ndr1-1, and M. Maeshima (Nagoya University) for pdr8-1 (pen3). This work was supported by a grant-in-aid for scientific research at Fukui Prefectural University to A. Ishikawa from Fukui Prefecture, Japan.

\section{LITERATURE CITED}

Aarts, N., Metz, M., Holub, E., Staskawicz, B. J., Daniels, M. J., and Parker, J. E. 1998. Different requirements for EDS1 and NDR1 by disease resistance genes define at least two $R$ gene-mediated signaling pathways in Arabidopsis. Proc. Natl. Acad. Sci. U.S.A. 95:1030610311.

Adie, B. A., Perez-Perez, J., Perez-Perez, M. M., Godoy, M., SanchezSerrano, J. J., Schmelz, E. A., and Solano, R. 2007. ABA is an essential signal for plant resistance to pathogens affecting JA biosynthesis and the activation of defenses in Arabidopsis. Plant Cell 19:1665-1681.

Alonso, J. M., Hirayama, T., Roman, G., Nourizadeh, S., and Ecker, J. R. 1999. EIN2, a bifunctional transducer of ethylene and stress responses in Arabidopsis. Science 284:2148-2152.

Assaad, F. F., Qiu, J. L., Youngs, H., Ehrhardt, D., Zimmerli, L., Kalde, M., Wanner, G., Peck, S. C., Edwards, H., Ramonell, K., Somerville, C. R., and Thordal-Christensen, H. 2004. The PEN1 syntaxin defines a novel cellular compartment upon fungal attack and is required for the timely assembly of papillae. Mol. Biol. Cell 15:5118-5129.

Basten, C. J., Weir, B. S., and Zeng, Z. B. 1994. Zmap QTL cartographer. Zmap-a QTL cartographer. Pages 65-66 in: Computing Strategies and Software, Vol. 22. Proceedings of the 5th World Congress on Genetics Applied to Livestock Production. C. Smith, J. S. Gavora, B. B. J. Chesnais, W. Fairfull, J. P. Gibson, B. W. Kennedy, and E. B. Burnside, eds. Guelph, Ontario, Canada.

Bednarek, P., Pislewska-Bednarek, M., Svatos, A., Schneider, B., Doubsky, J., Mansurova, M., Humphry, M., Consonni, C., Panstruga, R., SanchezVallet, A., Molina, A., and Schulze-Lefert, P. 2009. A glucosinolate metabolism pathway in living plant cells mediates broad-spectrum antifungal defense. Science 323:101-106.

Brodersen, P., Malinovsky, F. G., Hematy, K., Newman, M. A., and Mundy, J. 2005. The role of salicylic acid in the induction of cell death in Arabidopsis acd11. Plant Physiol. 138:1037-1045.

Buschges, R., Hollricher, K., Panstruga, R., Simons, G., Wolter, M., Frijters, A., Van Daelen, R., Van Der Lee, T., Diergaarde, P., Groenendijk, J., Topsch, S., Vos, P., Salamini, F., and Schulze-Lefert, P. 1997. The barley Mlo gene: A novel control element of plant pathogen resistance. Cell 88:695-705.

Cao, H., Bowling, S. A., Gordon, A. S., and Dong, X. 1994. Characterization of an Arabidopsis mutant that is nonresponsive to inducers of systemic acquired resistance. Plant Cell 6:1583-1592.

Century, K. S., Holub, E. B., and Staskawicz, B. J. 1995. NDR1, a locus of Arabidopsis thaliana that is required for disease resistance to both a bacterial and a fungal pathogen. Proc. Natl. Acad. Sci. U.S.A. 92:65976601.

Chen, J. G., Gao, Y., and Jones, A. M. 2006. Differential roles of Arabidopsis heterotrimeric G-protein subunits in modulating cell division in roots. Plant Physiol. 141:887-897.

Churchill, G. A., and Doerge, R. W. 1994. Empirical threshold values for quantitative trait mapping. Genetics 138:963-971.

Clay, N. K., Adio, A. M., Denoux, C., Jander, G., and Ausubel, F. M. 2009. Glucosinolate metabolites required for an Arabidopsis innate immune response. Science 323:95-101.

Collins, N. C., Thordal-Christensen, H., Lipka, V., Bau, S., Kombrink, E., Qiu, J. L., Huckelhoven, R., Stein, M., Freialdenhoven, A., Somerville, S. C., and Schulze-Lefert, P. 2003. SNARE-protein-mediated disease resistance at the plant cell wall. Nature 425:973-977.

Consonni, C., Humphry, M. E., Hartmann, H. A., Livaja, M., Durner, J., Westphal, L., Vogel, J., Lipka, V., Kemmerling, B., Schulze-Lefert, P., Somerville, S. C., and Panstruga, R. 2006. Conserved requirement for a plant host cell protein in powdery mildew pathogenesis. Nat. Genet. 38:716-720.

Dean, R. A., Talbot, N. J., Ebbole, D. J., Farman, M. L., Mitchell, T. K., Orbach, M. J., Thon, M., Kulkarni, R., Xu, J. R., Pan, H., Read, N. D., Lee, Y. H., Carbone, I., Brown, D., Oh, Y. Y., Donofrio, N., Jeong, J. S., Soanes, D. M., Djonovic, S., Kolomiets, E., Rehmeyer, C., Li, W., Harding, M., Kim, S., Lebrun, M. H., Bohnert, H., Coughlan, S., Butler, J., Calvo, S., Ma, L. J., Nicol, R., Purcell, S., Nusbaum, C., Galagan, J. E., and Birren, B. W. 2005. The genome sequence of the rice blast fungus Magnaporthe grisea. Nature 434:980-986.

Ebbole, D. J. 2007. Magnaporthe as a model for understanding hostpathogen interactions. Annu. Rev. Phytopathol. 45:437-456. 
Faivre-Rampant, O., Thomas, J., Allegre, M., Morel, J. B., Tharreau, D., Notteghem, J. L., Lebrun, M. H., Schaffrath, U., and Piffanelli, P. 2008. Characterization of the model system rice-Magnaporthe for the study of nonhost resistance in cereals. New Phytol. 180:899-910.

Glazebrook, J., and Ausubel, F. M. 1994. Isolation of phytoalexin-deficient mutants of Arabidopsis thaliana and characterization of their interactions with bacterial pathogens. Proc. Natl. Acad. Sci. U.S.A. 91:89558959.

Glazebrook, J., Rogers, E. E., and Ausubel, F. M. 1996. Isolation of Arabidopsis mutants with enhanced disease susceptibility by direct screening. Genetics 143:973-982.

Godiard, L., Sauviac, L., Torii, K. U., Grenon, O., Mangin, B., Grimsley, N. H., and Marco, Y. 2003. ERECTA, an LRR receptor-like kinase protein controlling development pleiotropically affects resistance to bacterial wilt. Plant J. 36:353-365.

Hashioka, Y., and Kusadome, H. 1975a. The mode of pseudoinfection of Pyricularia oryzae Cav. to the non-host plants. Res. Bull. Fac. Agric. Gifu Univ. 38:29-37.

Hashioka, Y., and Kusadome, H. 1975b. Ultrastructure of Pyricularia oryzae-nonhost interfaces. Res. Bull. Fac. Agric. Gifu Univ. 38:39-47.

Heath, M. C. 2000. Nonhost resistance and nonspecific plant defenses. Curr. Opin. Plant Biol. 3:315-319.

Heck, S., Grau, T., Buchala, A., Metraux, J. P., and Nawrath, C. 2003. Genetic evidence that expression of NahG modifies defence pathways independent of salicylic acid biosynthesis in the Arabidopsis-Pseudomonas syringae $\mathrm{pv}$. tomato interaction. Plant J. 36:342-352.

Howard, R. J., Ferrari, M. A., Roach, D. H., and Money, N. P. 1991. Penetration of hard substrates by a fungus employing enormous turgor pressures. Proc. Natl. Acad. Sci. U.S.A. 88:11281-11284.

Huitema, E., Vleeshouwers, V., Francis, D., and Kamoun, S. 2003. Active defence responses associated with non-host resistance of Arabidopsis thaliana to the oomycete pathogen Phytophthora infestans. Mol. Plant Pathol. 4:487-500.

Ikka, T., Kobayashi, Y., Iuchi, S., Sakurai, N., Shibata, D., Kobayashi, M., and Koyama, H. 2007. Natural variation of Arabidopsis thaliana reveals that aluminum resistance and proton resistance are controlled by different genetic factors. Theor. Appl. Genet. 115:709-719.

Ishikawa, A. 2009. The Arabidopsis G-protein $\beta$-subunit is required for defense response against Agrobacterium tumefaciens. Biosci. Biotechnol. Biochem. 73:47-52.

Ishikawa, A., Okamoto, H., Iwasaki, Y., and Asahi, T. 2001. A deficiency of coproporphyrinogen III oxidase causes lesion formation in Arabidopsis. Plant J. 27:89-99.

Jacobs, A. K., Lipka, V., Burton, R. A., Panstruga, R., Strizhov, N., Schulze-Lefert, P., and Fincher, G. B. 2003. An Arabidopsis callose synthase, GSL5, is required for wound and papillary callose formation. Plant Cell 15:2503-2513.

Jarosch, B., Jansen, M., and Schaffrath, U. 2003. Acquired resistance functions in mlo barley, which is hypersusceptible to Magnaporthe grisea. Mol. Plant-Microbe Interact. 16:107-114.

Jarosch, B., Collins, N. C., Zellerhoff, N., and Schaffrath, U. 2005. RAR1, RORI, and the actin cytoskeleton contribute to basal resistance to Magnaporthe grisea in barley. Mol. Plant-Microbe Interact. 18:397-404.

Jones, J. D., and Dangl, J. L. 2006. The plant immune system. Nature 444:323-329.

Kankanala, P., Czymmek, K., and Valent, B. 2007. Roles for rice membrane dynamics and plasmodesmata during biotrophic invasion by the blast fungus. Plant Cell 19:706-724.

Kobae, Y., Sekino, T., Yoshioka, H., Nakagawa, T., Martinoia, E., and Maeshima, M. 2006. Loss of AtPDR8, a plasma membrane ABC transporter of Arabidopsis thaliana, causes hypersensitive cell death upon pathogen infection. Plant Cell Physiol. 47:309-318.

Koga, H. 1994. Hypersensitive death, autofluorescence, and ultrastructural changes in cells of leaf sheaths of susceptible and resistant near-isogenic lines of rice (Pi-zt) in relation to penetration and growth of $P y$ ricularia oryzae. Botany 72:1463-1477.

Koga, H. 2001. Cytological aspects of infection by the rice blast fungus Pyricularia oryzae. Pages 87-110 in: Major Fungal Diseases of Rice Recent Advances. Kluwer Academic Publishers, Dordrecht, The Netherlands.

Koga, H., and Nakayachi, O. 2004. Morphological studies on attachment of spores of Magnaporthe grisea to the leaf surface of rice. J. Gen. Plant Pathol. 70:11-15.

Lawton, K., Weymann, K., Friedrich, L., Vernooij, B., Uknes, S., and Ryals, J. 1995. Systemic acquired resistance in Arabidopsis requires salicylic acid but not ethylene. Mol. Plant-Microbe Interact. 8:863-870.

Lease, K. A., Wen, J., Li, J., Doke, J. T., Liscum, E., and Walker, J. C. 2001. A mutant Arabidopsis heterotrimeric G-protein $\beta$ subunit affects leaf, flower, and fruit development. Plant Cell 13:2631-2641.

Lipka, V., Dittgen, J., Bednarek, P., Bhat, R., Wiermer, M., Stein, M.,
Landtag, J., Brandt, W., Rosahl, S., Scheel, D., Llorente, F., Molina, A. Parker, J., Somerville, S., and Schulze-Lefert, P. 2005. Pre- and postinvasion defenses both contribute to nonhost resistance in Arabidopsis. Science 310:1180-1183.

Lipka, U., Fuchs, R., and Lipka, V. 2008. Arabidopsis non-host resistance to powdery mildews. Curr. Opin. Plant Biol. 11:404-411.

Lister, C., and Dean, C. 1993. Recombinant inbred lines for mapping RFLP and phenotypic markers in Arabidopsis thaliana. Plant J. 4:745750.

Llorente, F., Alonso-Blanco, C., Sanchez-Rodriguez, C., Jorda, L., and Molina, A. 2005. ERECTA receptor-like kinase and heterotrimeric G protein from Arabidopsis are required for resistance to the necrotrophic fungus Plectosphaerella cucumerina. Plant J. 43:165-180.

Loehrer, M., Langenbach, C., Goellner, K., Conrath, U., and Schaffrath, U. 2008. Characterization of nonhost resistance of Arabidopsis to the Asian soybean rust. Mol. Plant-Microbe Interact. 21:1421-1430.

Lu, M., Tang, X., and Zhou, J. M. 2001. Arabidopsis NHO1 is required for general resistance against Pseudomonas bacteria. Plant Cell 13:437447.

Mellersh, D. G., and Heath, M. C. 2003. An investigation into the involvement of defense signaling pathways in components of the nonhost resistance of Arabidopsis thaliana to rust fungi also reveals a model system for studying rust fungal compatibility. Mol. Plant-Microbe Interact. 16:398-404.

Nawrath, C., and Metraux, J. P. 1999. Salicylic acid induction-deficient mutants of Arabidopsis express PR-2 and PR-5 and accumulate high levels of camalexin after pathogen inoculation. Plant Cell 11:13931404

Nishimura, M. T., Stein, M., Hou, B. H., Vogel, J. P., Edwards, H., and Somerville, S. C. 2003. Loss of a callose synthase results in salicylic acid-dependent disease resistance. Science 301:969-972.

Park, J. Y., Jin, J., Lee, Y. W., Kang, S., and Lee, Y. H. 2009. Rice blast fungus (Magnaporthe oryzae) infects Arabidopsis via a mechanism distinct from that required for the infection of rice. Plant Physiol. 149:474486.

Shafiei, R., Hang, C., Kang, J.-G., and Loake, G 2007. Identification of loci controlling non-host disease resistance in Arabidopsis against the leaf rust pathogen Puccinia triticina. Mol. Plant Pathol. 8:773-784.

Shimada, C., Lipka, V., O'Connell, R., Okuno, T., Schulze-Lefert, P., and Takano, Y. 2006. Nonhost resistance in Arabidopsis-Colletotrichum interactions acts at the cell periphery and requires actin filament function. Mol. Plant-Microbe Interact. 19:270-279.

Singer, T., Fan, Y., Chang, H. S., Zhu, T., Hazen, S. P., and Briggs, S. P. 2006. A high-resolution map of Arabidopsis recombinant inbred lines by whole-genome exon array hybridization. PLoS Genet. 2:e144.

Staswick, P. E., Su, W., and Howell, S. H. 1992. Methyl jasmonate inhibition of root growth and induction of a leaf protein are decreased in an Arabidopsis thaliana mutant. Proc. Natl. Acad. Sci. U.S.A. 89:68376840

Stein, M., Dittgen, J., Sanchez-Rodriguez, C., Hou, B. H., Molina, A. Schulze-Lefert, P., Lipka, V., and Somerville, S. 2006. Arabidopsis PEN3/PDR8, an ATP binding cassette transporter, contributes to nonhost resistance to inappropriate pathogens that enter by direct penetration. Plant Cell 18:731-746.

Suharsono, U., Fujisawa, Y., Kawasaki, T., Iwasaki, Y., Satoh, H., and Shimamoto, K. 2002. The heterotrimeric G protein $\alpha$ subunit acts upstream of the small GTPase Rac in disease resistance of rice. Proc. Natl. Acad. Sci. U.S.A. 99:13307-13312.

Temple, B. R., and Jones, A. M. 2007. The plant heterotrimeric G-protein complex. Annu. Rev. Plant Biol. 58:249-266.

Tor, M., Gordon, P., Cuzick, A., Eulgem, T., Sinapidou, E., Mert-Turk, F., Can, C., Dangl, J. L., and Holub, E. B. 2002. Arabidopsis SGT1b is required for defense signaling conferred by several downy mildew resistance genes. Plant Cell 14:993-1003.

Tornero, P., Merritt, P., Sadanandom, A., Shirasu, K., Innes, R. W., and Dangl, J. L. 2002. RARl and NDR1 contribute quantitatively to disease resistance in Arabidopsis, and their relative contributions are dependent on the $R$ gene assayed. Plant Cell 14:1005-1015.

Trusov, Y., Rookes, J. E., Chakravorty, D., Armour, D., Schenk, P. M., and Botella, J. R. 2006. Heterotrimeric G proteins facilitate Arabidopsis resistance to necrotrophic pathogens and are involved in jasmonate signaling. Plant Physiol. 140:210-220.

Trusov, Y., Sewelam, N., Rookes, J. E., Kunkel, M., Nowak, E., Schenk, P. M., and Botella, J. R. 2008. Heterotrimeric G proteins-mediated resistance to necrotrophic pathogens includes mechanisms independent of salicylic acid-, jasmonic acid/ethylene- and abscisic acid-mediated defense signaling. Plant J. 58:69-81.

Van Wees, S. C., and Glazebrook, J. 2003. Loss of non-host resistance of Arabidopsis NahG to Pseudomonas syringae pv. phaseolicola is due to degradation products of salicylic acid. Plant J. 33:733-742. 
Van Zanten, M., Snoek, L. B., Proveniers, M. C., and Peeters, A. J. 2009. The many functions of ERECTA. Trends Plant Sci. 14:214-218.

Vogel, J., and Somerville, S. 2000. Isolation and characterization of powdery mildew-resistant Arabidopsis mutants. Proc. Natl. Acad. Sci. U.S.A. 97:1897-1902.

Vogel, J. P., Raab, T. K., Schiff, C., and Somerville, S. C. 2002. PMR6, a pectate lyase-like gene required for powdery mildew susceptibility in Arabidopsis. Plant Cell 14:2095-2106.

Vogel, J. P., Raab, T. K., Somerville, C. R., and Somerville, S. C. 2004. Mutations in PMR5 result in powdery mildew resistance and altered cell wall composition. Plant J. 40:968-978.

Wilson, R. A., and Talbot, N. J. 2009. Under pressure: Investigating the biology of plant infection by Magnaporthe oryzae. Nat. Rev. Microbiol. 7:185-195.

Xie, D. X., Feys, B. F., James, S., Nieto-Rostro, M., and Turner, J. G.
1998. COI1: An Arabidopsis gene required for jasmonate-regulated defense and fertility. Science 280:1091-1094.

Yoshii, H. 1949. Patho-histologic observations on tomato inoculated with Pyricularia oryzae, the rice-blast fungus. Ann. Phytopathol. Soc. Jpn. 13:14-18.

Yun, B. W., Atkinson, H. A., Gaborit, C., Greenland, A., Read, N. D. Pallas, J. A., and Loake, G. J. 2003. Loss of actin cytoskeletal function and EDS1 activity, in combination, severely compromises non-host resistance in Arabidopsis against wheat powdery mildew. Plant J. 34:768777.

Zhang, Z., Lenk, A., Andersson, M., Gjetting, T., Pedersen, C., Nielsen, M., Newman, M.-A., Hou, B.-H., Somerville, S., and Thordal-Christensen, H. 2008. A lesion-mimic syntaxin double mutant in Arabidopsis reveals novel complexity of pathogen defense signaling. Mol. Plant-Microbe Interact. 1:510-527. 